\title{
Quality of Life of Children with Cerebral Palsy: Accumulative Effect of Physiotherapy Intervention in North Central and Southwest Nigeria
}

\author{
Saka M.J', Odunewu M.A ${ }^{2}$, Saka A.O. ${ }^{3}$, Akinwale S.G. ${ }^{4}$, Anjorin O.U. ${ }^{4}$ \\ ${ }^{1}$ Department of Epidemiology and Community Health, Faculty of Clinical Sciences, College of Health Sciences, \\ University of Ilorin, Ilorin Nigeria. \\ ${ }^{2}$ Department of Physiotherapy Paediatric Unit. General Hospital, Eruwa, Oyo State Hospitals Management Board, \\ Oyo State, Nigeria. \\ ${ }^{3}$ Department of Paediatric and Child Health, Faculty of Clinical Sciences, College of Health Sciences, University of \\ Ilorin, Ilorin, Nigeria. \\ ${ }^{4}$ Department of Physiotherapy Paediatric Unit, University of Ilorin Teaching Hospital, Ilorin, Kwara State, \\ Nigeria.
}

\section{Correspondence}

M.J. Saka, Department of Epidemiology and Community Health, Faculty of Clinical Sciences, College of Health Sciences, University of Ilorin, Ilorin Nigeria・Email sakamj1@yahoo.com

\begin{abstract}
SUMMARY
Quality of life (QoL) has emerged as an important concept in child health. Cerebral palsy (CP) is a life-limiting disorder that is not curable, but the QoL of children with CP can be improved after early neurodevelopmental treatment, such that the affected child can be as independent as possible in carrying out activities of daily living. The purpose of this study was to determine the accumulative effect of physiotherapy treatment on QoL in children with CP.

One hundred and twenty male and female children with CP, aged 2 to 8 years, were randomly selected for the study. After their medical history had been taken and diagnosis made, treatment was instituted with the ultimate aims of acquiring advanced postural reactions, strengthening weak back and abdominal muscles, and stimulating cognitive and mental ability. The approaches included passive movement, mobilization to prevent joint stiffness and stretching of stiff joints, and early neurodevelopmental treatment through the use of therapy wedges, rolls and therapy balls to facilitate rolling, sitting and standing. Aids such as standing frames, stimulating toys and diagrams were used to enhance the children's state of mental health.

Accumulated physiotherapy treatment had beneficial and statistically significant effect on the QoL (mean score of $54.98 \% \pm 13.1 \%)$ of children with CP in North Central and South West Nigeria $(P<0.05)$. It was also found that physiotherapy intervention improves the quality of life of children with cerebral palsy, particularly those who are engaged early enough, and that parental level of education contributes positively to improved quality of life among children with cerebral palsy.
\end{abstract}

KEY WORDS: Quality of life, cerebral palsy, physiotherapy intervention

\section{INTRODUCTION}

Cerebral palsy (CP) is not a single disease but a name given to a wide variety of static impairment syndromes occurring secondary to a lesion in the developing brain (Daichmam et al, 2003). The majority of these syndromes occur during the prenatal period; $10 \%$ of cases can be attributed to 
neonatal asphyxia and, in most of the cases, are idiopathic (Ogunlesi and Ogundeji, 2008). Omole and Olaogun (2012) described different types of cerebral palsy, including spastic CP which contributes $70 \%$ to $80 \%$ of cases. Others are ataxic, athetoid, and flaccid $\mathrm{CP}$, but the majority are mixed as some of the spastic CP children could retain flaccidity in the trunk (Rosenbaum et al, 2007).

Ogunlesi et al (2008) found that CP constitutes the most common neurological condition among young children and its prevalence at the paediatric neurologic unit in Olabisi Onabanjo University Teaching Hospital (OOUTH), Sagamu was $50.3 \%$. A study on socio-clinical issues in CP (Ogunlesi et al., 2008) revealed that the majority of babies with $\mathrm{CP}$ were delivered in primary health care centres or by traditional birth attendants. Early intervention services include medication; physical therapy to reduce muscle spasticity, for balance training, and to improve postural control; as well as counselling and social support (Zeinab and Gehan, 2015). Intervention is aimed at enabling the highest possible functioning and integration at home and in the community. Other combined approaches include ankle taping for instance, in hemiplegic cerebral palsy, the use of adjunct assistive technology such as neuromuscular electrical stimulation, and reciprocal electrical stimulation (Wanees and Mohamed, 2015; Daichman et al., 2003).

The World Health Organization Quality of Life Assessment (1995) reports that quality of life (QoL) is an important concept in child health. Little is known about the QoL of children with disabilities, especially at the more severe end of the spectrum of CP. However, Eiser and Morse (2001) nd Ravens-Sieberer and Gosch (2001) reported that QoL is generally accepted as a subjective concept and therefore should be self-reported by the individual whenever possible. Riley (2004) showed that evidence is accumulating that children can self-report QoL reliably, provided their emotional development, cognitive ability, and reading level are taken into account. However, it may not be possible to obtain reliable information from children with severe intellectual impairment or significant communication problems, therefore, the use of proxies (usually mothers) for the assessment of QoL in such children is necessary (Eiser and Morse, 2001).

Previous studies carried out by Jemta et al,(2005) and Varni et al, (2005) provide conflicting evidence about the relationship between QoL and severity of motor impairment and suggest that domains related to physical symptoms may be more affected than social or emotional functioning domains (Vargus-Adams et al, 2005; Kennes et al 2002).
This may be attributable in part to the fact that physical aspects are more easily reported than psychological aspects because in children, it is difficult to separate physical mobility from cognitive and perceptual skill acquisition. However, a few studies examined the influence of other impairments in this population. Social contacts and activities with peers are reported to be reduced by chronic pain. A previous study, mainly from the general population, has suggested that children from lower socioeconomic backgrounds have significantly more negative experiences with regard to health and well-being, but there is insufficient evidence to determine whether a similar relationship holds for children with disabilities (Houlihan et al 2004).

Parents' views of their children's QoL may also be affected by the burden of caregiving and their own mental health and well-being. Studies on the QoL of children with CP have focused mainly on small groups of children selected from clinics with homogeneous degrees of impairment severity, rather than the spectrum of impairments.

The null hypothesis is that there is no significant influence of physiotherapy intervention on QoL of children with $\mathrm{CP}$ and that there is no significant influence of parents' level of education on QoL of children with CP. Therefore, the aim of the study was to evaluate the effect of physiotherapy intervention and influence of care givers' educational status on the overall health-related QoL of children with $\mathrm{CP}$.

\section{METHOD}

\section{Study Design}

The study was a descriptive cross-sectional survey conducted at the selected tertiary health facilities of University of Ilorin Teaching Hospital (UITH), Ilorin, Kwara State; Adeoyo Maternity Teaching Hospital, Yemetu, Ibadan in Oyo State; and Ladoke Akintola University of Technology Teaching Hospital (LAUTECH), Ogbomoso, Oyo State, all in Nigeria. The quantitative data was collected using a standard questionnaire. Children aged 2-8 years that were affected with $\mathrm{CP}$, who were attending the selected clinics for treatment and were residing in Kwara and Oyo states were included in the study.

\section{Participants}

A sample size of 120 was determined using Fisher's formula for estimating sample size to determine the proportion of a factor where the population is less than 
10,000. One hundred and twenty children with CP who were attending clinics in the physiotherapy department of the teaching hospitals and whose parents gave informed consent were randomly selected for the study (Fischer et al, 1998).

\section{Instruments}

The Cerebral Palsy Quality of Life Questionnaire (CP QoLChild) was used for the study. It was designed for children aged 4-12 years. The CP QoL-Child measures seven areas of a child's life which include: social wellbeing and acceptance, participation and physical health, feelings about functioning, emotional wellbeing and self-esteem, pain and impact of disability, access to services, and family health.

The Gross Motor Function Classification System (GMFCS) is a five-level classification system that focuses on the voluntary movements of children with cerebral palsy (CP), with special focus on walking and sitting. The higher the level in GMFCS, the more severe the CP. The GMFCS applies to all types of CP and all levels of severity. The level of improvement in gross motor function was assessed through a questionnaire that subjectively measured the GMFCS level of each child before intervention (baseline) and after intervention and both levels compared (Marta et al, 2014).

\section{Assessment Tool and Pre-test}

Ten percent $(10 \%)$ of the sample size (120) were used to pre-test the questionnaire for reliability. This was carried out at the Physiotherapy Department of Sobi Specialist Hospital, Ilorin, Kwara State, which has the same characteristics as the selected tertiary health facilities. The questionnaire was re-arranged; appropriate items were put under the right domains, without adding or removing anything, before it was applied to the selected respondents. After informed consent had been granted by the participants, they were recruited from the out-patient paediatric units of the physiotherapy clinics in UITH Ilorin, Adeoyo Maternity Teaching Hospital, Yemetu, Ibadan and LAUTECH, Ogbomoso.

\section{Sampling Technique}

Simple random sampling was used to select Kwara and Oyo states in North Central and South-West Nigeria and proportionate allocation of sample size was used to determine the number of respondents based on their population in each of the physiotherapy clinics. The first participant was randomly selected through balloting while systematic sampling technique was used to recruit subsequent participants. This was done for each of the health facilities.

\section{Ethical Approval}

Ethical approval was sought and obtained from the University of Ilorin Research Ethics Committee before the study commenced. Informed consent for participation was obtained from the parents of the selected children before inclusion in the study. The study was at no cost to the respondents and all information obtained was kept confidential.

\section{Therapy Methods}

The specific treatment used in each of the physiotherapy paediatric units selected for this study was based on developmental milestones, age, presenting complaints and functional limitation. According to Nadire (2010), the physical treatment modalities include range of motion exercises, strengthening exercises and neurodevelopmental technique (NDT), to stimulate the central nervous system and to establish normal patterns of movement. Treatment sessions last between forty-five minutes and two hours at a frequency of one to two times per week for six successive months. The focus is to improve quality of life, motor control, postural control, strength; increase range of motion, mobility skills, muscular/cardiovascular endurance; increase coordination; improve balance; decrease spasticity and contractures; ensure normal joint alignment; teach correct use of assistive devices, etc. Conventional exercises consist of active and passive range of motion exercises, stretching, strengthening and fitness to improve the cardiovascular condition (Narayanan and Fehlings, 2006).

Passive movement/stretching of stiff joints, the use of the neuro-developmental ball to teach advance postural reactions as well as strengthening weak back and stomach muscles, rolling and kneeling exercises as well as sitting and standing education using sitting and standing frames respectively for children with delayed developmental milestones and stimulating toys and diagrams to stimulate the child's state of mental health, etc. were the treatment modalities used in this study. In all the study centres, each patient was treated once a week for 2 hours over a period of 6 weeks.

\section{Data Analysis}

\section{Scoring the CP QoL-Child}

The CP-QoL used for data collection has seven domains 
with 65 items. Each item is rated 1-9 except item 4 under pain and impact of disability domain which is rated $1-5$. If an item is scored 1 , then it is recorded as $0 \%$, if the score is 2 , it is recorded as $12.5 \%$, and so on with an interval of 12.5 , until it gets to 9 which is recoded as $100 \%$. For item 4 however, a score of $1=0 \%, 2=25 \%, 3=50 \%, 4=75 \%$, $5=100 \%$. The mean score in each domain or the overall mean score was calculated as the overall score for the health-related quality of life of the participant.

The data collected were analysed using SPSS version 19.0. Descriptive statistics of frequency, percentage, and mean and standard deviation were used to summarize the data collected. The t-test was used to test for significant difference influence of parents educational status on QoL of children with CP. Analysis of variance (ANOVA) was used to analyse the significant difference between cost and health-related quality of life of the participants and level of significance was set at 0.05 .

\section{RESULTS}

More of the participants, $71(59 \%)$, were male; while 49 $(41 \%)$ were female. The age range was 2 to 8 years with a mean age of $4.1 \pm 1.7$ years (table 1 ). The majority, $68(56.7 \%)$, of the children with CP had good social wellbeing and acceptance, and about two-thirds, 84(70\%), had poor level of participation, while $89(74.2 \%)$ had good emotional well-being and self-esteem (table 2). The results show that the majority of the children, $68(56.7 \%)$, started physiotherapy treatment late; only $52(43.3 \%)$ started early (table 3).

Table 1. Socio-demographic characteristics of the participants $(\mathrm{N}=$ 120)

\begin{tabular}{lll}
\hline Variables & Frequency & Percentage \\
\hline Age (years) & 78 & 65.0 \\
$2-4$ & 30 & 25.0 \\
$4-6$ & 12 & 10.0 \\
$7-8$ & & \\
Gender & 71 & 59.0 \\
Male & 49 & 41.0 \\
Female & & \\
Occupation of Care Givers & 47 & 39.0 \\
Civil Servant & 36 & 30.0 \\
Trading & 4 & 3.0 \\
Student & 8 & 7.0 \\
Unemployed & 25 & 21.0 \\
Others & & \\
Educational Status of Care Givers & 45 & 38.0 \\
Pre-Secondary School Certificate & 75 & 62.0 \\
Post-Secondary School Certificate & 75 & \\
\hline
\end{tabular}

Table 2. Health-related quality of life domains

\begin{tabular}{llll}
\hline Domains & Mean Scores in \% & Frequency & Percentage \\
\hline $\begin{array}{l}\text { Social Well- } \\
\text { being \& }\end{array}$ & $0-49$ & 52 & 43.3 \\
Acceptance & $50-100$ & 68 & 56.7 \\
Feelings About & $0-49$ & 64 & 53.3 \\
Function & $50-100$ & 56 & 46.7 \\
Participation \& & $0-49$ & 84 & 70.0 \\
Physical Health & $50-100$ & 36 & 30.0 \\
Emotional Well- & $0-49$ & 31 & 25.8 \\
being \& Self- & $50-100$ & 89 & 74.2 \\
Esteem & $0-49$ & 59 & 49.2 \\
Pain \& Impact of & $50-100$ & 61 & 50.8 \\
Disability & $0-49$ & 109 & 90.8 \\
Access to & $50-100$ & 11 & 9.0 \\
Services & $0-49$ & 14 & 11.7 \\
& $50-100$ & 106 & 88.3 \\
Family Health & & & \\
\hline
\end{tabular}

Table 3. Early and late physiotherapy intervention

\begin{tabular}{lcc}
\hline Intervention & Frequency & Percentage \\
\hline Early Intervention & 52 & 43.3 \\
Late Intervention & 68 & 56.7 \\
Total & 120 & 100.0 \\
\hline
\end{tabular}

Having undergone physiotherapy treatment, the outcome of the study revealed that less than half, 49(40.8\%), were mildly affected, 16 (13.3\%) were moderately affected while $55(45 \%)$ were still seen to remain at the severely affected level. The majority of the children who had improved motor functions following physiotherapy interventions, $65(54.2 \%)$, were those in GMFCS level 1 to level 3. However, there was no appreciable level of improvement among the 55 (45.8\%) participants with severe GMFCS, level 4 and level 5 (figure 1). Improved GMFCS level among children with cerebral palsy has been linked with improved health-related quality of life. The outcome of this study showed that the children with $\mathrm{CP}$ had a moderate health-related QoL with a mean score of $54.98 \% \pm 13.1 \%$ having received physiotherapy treatment in the selected tertiary hospitals (table 2). Out of those children with CP whose parents had pre-secondary education and post-secondary education, 19 (42\%) and $46(62 \%)$ respectively were reported to have improved having received physiotherapy intervention while $26(58 \%)$ and 29 (39\%) respectively recorded no improvement. The study shows that there was statistically significant influence 
of parental education on QoL improvement of children with CP ( $p<0.005)$ (table 4). The outcome of the study shows that more than half of the children with $\mathrm{CP}$ showed improvement after series of neuro-developmental therapy (figure 2).

Table 4. Level of improvement among children of parents with preand post-secondary school qualifications

\begin{tabular}{lccc}
\hline Qualifications & W. Improvement & N. improvement & Total \\
\hline PreSec.SchCert & $19(42 \%)$ & $26(58 \%)$ & $45(100 \%)$ \\
PostSecSchCert & $46(61 \%)$ & $29(39 \%)$ & $75(100 \%)$ \\
Total & $65(54 \%)$ & $55(46 \%)$ & $120(100 \%)$ \\
\hline
\end{tabular}

W. Improvement- with improvement \& N. Improvement- no improvement

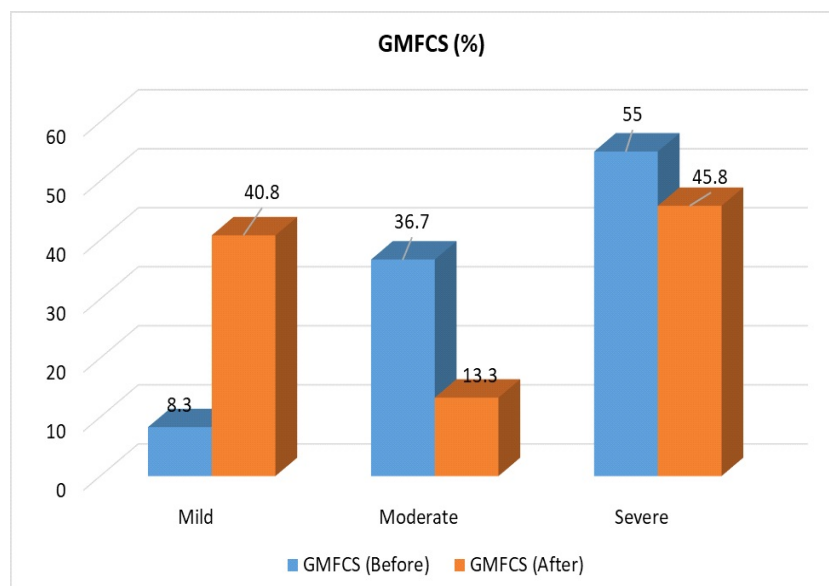

Figure 1. Severity of motor functions before and after physiotherapy interventions.

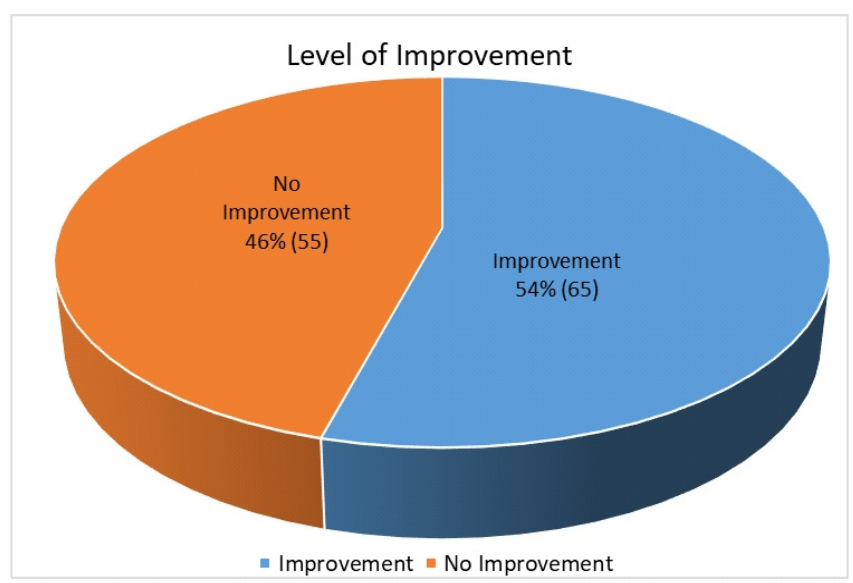

Figure 2. Level of improvement among children with cerebral palsy

\section{DISCUSSION}

The results of this study indicate that the majority of the children with $\mathrm{CP}$ were male with a male to female ratio of 1.5 to 1.0 . This agrees with the outcomes of the studies by
Adebimpe et al (2013) and Tella et al (2011) in south west and south east Nigeria respectively, and a study carried out at University of Nigeria Teaching Hospital, Enugu on the effect of neuro-developmental therapy on disability level of subjects with cerebral palsy by Ezema et al (2004). The age group of the majority of the children with $\mathrm{CP}$ was between 2 and 4 years, which may be a reflection of the fact that as children with CP get older, there is a reduction in their potential to achieve an appreciable level of improvement in their motor function skills, hence most care givers are discouraged and abscond from the health facilities. This is corroborated by the study by Lawal et al (2014) conducted at Ahmadu Bello University, Zaria on the socio-economic challenges of parents of children with neurological disorders, in which the participants in the higher age groups began to reduce after four years, leaving the 1-2 years age group in the majority.

The outcome of this study shows that the greater percentage of the care givers $(62 \%)$ had post-secondary school qualifications which is similar to the findings of a study in Kogi State conducted by Awoyemi et al (2011), in which the increased educational status of the parents helped in taking health-seeking decisions concerning the children or siblings of the children with $\mathrm{CP}$, particularly in the utilization of modern health facilities for various curative interventions.

The outcome of this study shows that the children with CP had moderate health-related QoL, which is corroborated by other studies (Jimoh, 2014; Emerson, 2003; Eseigbe et al, 2014). However, it differed from another study (Mc Manus et al, 2008) which observed a high prevalence of severe impairment in gross motor function among children with cerebral palsy and that there was limited utilization of assistive mobility devices particularly among those with GMFCS levels 4 and 5; this impaired gross motor function has been linked with low QoL.

Despite the fact that a high overall mean score was recorded in the QoL domain, a high majority of the children with CP had poor level of participation and physical wellbeing. This finding is similar to a study by Arnaud et al (2008) in South West Ireland on participation in everyday activities and QoL in pre-teenage children living with $\mathrm{CP}$, which found that increased impairment due to $\mathrm{CP}$ restricts participation in the majority of everyday activities, however, level of participation had a limited effect on the quality of life of children with CP. In addition, a significant number of participants in a study by Marta et al (2014) had poor mean scores in four different domains of health-related 
QoL, which corroborated a study conducted in Europe which found that, depending on the domains of life, the most severely impaired children in terms of motor function do not always have the poorest QoL.

The result from this study show that more than half of the children with CP had poor mean scores under pain and impact of disability domain of QoL though the majority had good mean scores under emotional wellbeing and selfesteem. This may be due to the fact that pain in children with $\mathrm{CP}$ is responsible for the reduction in the psychological domain of health-related QoL as documented in other study (Varni et al, 2005). The result of the study by Varni et al (2005) equally showed that most children with CP had good social wellbeing and acceptance having received physiotherapy intervention. The reason for this may be that interventions which focus on reducing physical or mental impairment possibly lead to improvements in the psychosocial QoL of children with CP.

Some early intervention programmes can have longlasting effects on outcomes such as school performance, psychosocial skills (Blauw-Hospers and Dirks, 2007) and perceptual-motor skills (Brooks-Gunn and Liaw, 1992). For infants born preterm, some interventions provided in the first year of life may advance cognition, receptive language, visual-motor and spatial skills at preschool age. The results of the studies by Spittle (2007) and Karande et al (2008) are similar to the findings of this study which show a significant difference between early and late physiotherapy intervention on gross motor functions and overall health-related quality of life of children with cerebral palsy.

Improved gross motor function has been linked with improved health-related quality of life in this study which is contrary to another study (Marta et al, 2004) which compared the influence of functional level, ambulatory and physical activity performance on self-reported health status and QoL of children with CP and concluded that functional level and performance did not influence QoL of affected children.

The result of this study shows that the higher the educational status of parents of children with $\mathrm{CP}$, the better the health-related QoL of the children. This is contrary to the finding in a study (Palisano, 2010) in New Delhi on the impact of educational status on parental knowledge of children with CP which found no significant relationship between educational status of parents and parental knowledge of $\mathrm{CP}$ to improve management and the overall QoL of children with CP. The findings in this study may be a reflection of the fact that most mothers were delayed in starting child bearing while pursuing tertiary education, which could be a risk factor for cerebral palsy or a reflection of the fact that parents' level of education aided their awareness in seeking appropriate intervention for their wards.

\section{CONCLUSION}

The outcome of this study showed that the children with CP had a high mean score in health-related QoL and moderate improved health-related QoL after physiotherapy treatment in the selected tertiary hospitals and the educational status of the parents had significant influence on the treatment outcome of QoL of their children with CP.

\section{Financial Support and Sponsorship}

Nil.

\section{Conflicts of Interest}

There was no conflict of interest

\section{References}

Adebimpe O.O., Olubusola E.J., Morenike C.O., Olaogun M.O.B. 2013. Gross motor function in cerebral palsy: The association with age, motor type and topographic distribution. Nigerian Journal of Medical Rehabilitation 16(2): 1-15.

Arnaud C., White-Koning M., Michelsen S.I., Parkes J., Thyen U. et al. 2008. Parent-reported quality of life of children with cerebral palsy in Europe. Journal of America Academy of Paediatrics 121: 54-64.

Awoyemi T.T, Obayelu O.A, Opaluwa H.I. 2011. Effect of distance on utilization of health care services in rural Kogi State, Nigeria. Journal of Human Ecology 35(1): 1-9.

Blauw-Hospers C. H, de Graaf- Peters V. B., Dirks T. et al. 2007. Does early intervention in infants at high risk for a developmental motor disorder improve motor and cognitive development? Neuroscience and Biobehavioural Review 31: 1201-1212.

Brooks-Gunn J., Liaw F.R., Klebanov P.K. 1992. Effects of early intervention on cognitive function of low-birth weight preterm infants. Journal of Pediatrics 120: 350-359.

Daichman J., Johnston T.E., Evans K., Tecklin J.S. 2003. The effects of a neuromuscular electrical stimulation home program on impairments and functional skills of a child with spastic diplegic cerebral palsy: A case report. Pediatr Phys Ther 15: 153-158.

Eiser C., Morse R. 2005. Quality-of-life measures in chronic diseases of childhood. Health Technology Assessment 5: $1-157$.

Emerson E. 2003. Mothers of children and adolescents with intellectual disability: Social and economic situations, mental health status and self-assessed social and psychological impact 
of the child's difficulties. Journal of Intellectual Disability 47(4): 385-399.

Eseigbe E.E., Anyiam J.O., Wammanba R.D., Obajuluwa S.O., Rotibi, B.B. et al. 2014. A review of gross motor function in children with cerebral palsy in Zaria, North-Western Nigeria. International Journal of Physical Medicine and Rehabilitation $2: 236$

Ezema C.I., Lamina S., Nkama R.E., Ezugwu U.A., Amaeze A.A., Nwankwo M.J. 2004. Effect of neuro-developmental therapy on disability level of subjects with cerebral palsy receiving physiotherapy at the University of Nigeria Teaching Hospital, Enugu, Nigeria. Nigeria Journal of Paediatrics 41(2):116-119.

Fischer A.A., Lang J.E., Stockel J.E., Townsend J.W. 1998. Sampling Handbook for Family Planning and Operation Design. 2nd edition. New York: Population Council New York, pp. 45.

Houlihan C.M., O’Donnell M., Conaway M., Stevenson R.D. 2004. Bodily pain and health-related quality of life in children with cerebral palsy. Developmental and Child Neurology 46: 305-310.

Jemta L., Dahl M., Fugl-Meyer K.S., Stensman, R. 2005. Wellbeing among children and adolescents with mobility impairment in relation to demographic data and disability characteristics. Journal of Paediatrics 94: 616-62.

Jimoh A.O. 2014. Utilization of health care services in rural and urban areas: A determinant factor in planning and managing health care delivery systems in Kwara State, Nigeria. Journal of African Health Science 14(2): 322-333.

Karande S., Patil S., Kulkarni, M. 2008. Impact of an educational program on parental knowledge of cerebral palsy. Indian Journal of Pediatrics 75: 1-6.

Kennes J., Rosenbaum P., Hanna S.E., et al. 2002. Health status of school-aged children with cerebral palsy: Information from a population-based sample. Developmental Medicine Child Neurology 44: 240-247.

Lawal H., Anyebe E.E., Obiako D.R., Garba S.N. 2014. Socioeconomic challenges of parents of children with neurological disorders: A hospital-based study in North West Nigeria. International Journal of Nursing and Midwifery 6(4): 58-66.

Marta B., Inmaculada R., Begona O., Raquel A., Egmar L., Pedro M. 2014. The impact of pain on health-related quality of life and motor function in individuals with cerebral palsy as reported by health professional. BMC Pediatrics Journal 14: 192.

Mc Manus V., Corcoran P., Perry, I.J. 2008. Participation in everyday activities and quality of life in pre-teenage children living with cerebral palsy in South West Ireland. BMC Paediatrics 8: 50.

Nadire B., Selim Y., Lana S. Risk factors of cerebral palsy. 2010. In: Textbook of the Help Guide to Cerebral Palsy, 2nd edition. Washington: Rotamat Press Co. Ltd, pp.7-8.
Narayanan U.G., Fehlings D., Weir S. 2006. Initial development and validation of the caregiver priorities and child health index of life with disabilities. Developmental Medicine and Child Neurology 48: 804-812.

Ogunlesi T., Ogundeji M., Ogunfowora O., Olowu, A. 2008. A. Socio-clinical issues in cerebral palsy in Sagamu, Nigeria. Journal of Child Health 2: 3-10.

Omole J.O., Olaogun M.O.B., Mbada C.E. 2012. Paediatric neurological conditions seen at the Physiotherapy Department of OAUTH, Ile-Ife, Nigeria. African Journal of Biomedical Research 14: 183-186.

Palisano, R.J., Orlin, M.N., Chiarello, L.A. et al. (2010). Family needs of parents of children and youth with cerebral palsy. Child: Care, Health and Development 36(1): 85-92.

Ravens-Sieberer U., Gosch A., Abel T., et al. 2001. Quality of life in children and adolescents: A European public health perspective. European Journal of Preventive Medicine 46: 294-302.

Riley A.W. 2004. Evidence that school-age children can self-report on their health. Ambulation and Pediatrics Journal 4(1): 371-376

Rosenbaum P., Paneth N., Leviton A. 2007. Cerebral palsy: A reconceptualization of the spectrum. Journal of Biomedical Research 142: 3-7.

Spittle A., Orton J., Doyle L. 2007. Early developmental intervention programs post hospital discharge to prevent motor and cognitive impairments in preterm infants. Cochrane Database Systematic Review (2): 5495.

Tella B.A., Gbiri C.A., Osho O.A., Ogunrinu A.E. 2011. Healthrelated quality of life of Nigerian children with cerebral palsy. DCID Journal 22: 2-10.

Vargus-Adams J. 2005. Health-related quality of life in childhood cerebral palsy. Archive of Physical Medicine and Rehabilitation 86: 940-945.

Varni J.W., Burwinkle T.M., Sherman S.A., et al. 2005. Healthrelated quality of life of children and adolescents with cerebral palsy: Hearing the voices of the children. Developmental Medicine and Child Neurology 47: 592-597.

Wanees M.B., Mohamed B.I. 2015. Balance training versus reciprocal electrical stimulation on knee joint alignment in spastic diplegic cerebral palsy children. Bulletin of Faculty of Physical Therapy 20: 146-153.

World Health Organization. 1995. The World Health Organization Quality of Life assessment (WHOQoL): Position paper from the World Health Organization. Social Science in Medicine 41: 1403-1409.

Zeinab A.H., Gehan H. 2015. Accumulative effect of ankle kinesio taping on postural control in children with hemiparetic cerebral palsy. Bulletin of Faculty of Physical Therapy 20: 154-160. 